\title{
Rationale for Targeting CD6 as a Treatment for Autoimmune Diseases
}

\author{
Ruby Alonso-Ramirez, ${ }^{1,2}$ Séverine Loisel, ${ }^{1}$ Caroline Buors, ${ }^{1}$ Jacques-Olivier Pers, ${ }^{1}$ \\ Enrique Montero, ${ }^{2}$ Pierre Youinou, ${ }^{1,3}$ and Yves Renaudineau ${ }^{1,3}$ \\ ${ }^{1}$ EA2216 Immunology and Pathology and IFR 148 ScInBioS, European University of Brittany, BP 824, 29609 Brest, France \\ ${ }^{2}$ Experimental Immunotherapy Department, Center for Molecular Immunology, P.O. Box 16040, 11600 La Havana, Cuba \\ ${ }^{3}$ Laboratory of Immunology, CHU Brest, Brest University Medical School Hospital, BP 824, 29609 Brest, France
}

Correspondence should be addressed to Pierre Youinou, youinou@univ-brest.fr

Received 16 August 2010; Accepted 22 December 2010

Academic Editor: Deh-Ming Chang

Copyright ( $\odot 2010$ Ruby Alonso-Ramirez et al. This is an open access article distributed under the Creative Commons Attribution License, which permits unrestricted use, distribution, and reproduction in any medium, provided the original work is properly cited.

\begin{abstract}
CD6 is a 105-130 kDa surface glycoprotein expressed on the majority of T cells and a subset of B cells. The human $c d 6$ gene maps to chromosome 11, and the expression of its protein product is tightly regulated. CD6 mediates cellular adhesion migration across the endothelial and epithelial cells. In addition, it participates in the antigen presentation by B cells and the subsequent proliferation of T cells. CD6 may bind in trans to surface glycoproteins (such as ALCAM and 3A11), or to microbial lipopolysaccharides, and may bind in cis to endogenous ligands (such as CD3 and CD5), and thereby deliver a costimulatory signal. Transinteractions are reinforced during autoimmune diseases (e.g., rheumatoid arthritis (RA), Sjögren's syndrome, and multiple sclerosis) and some cancers. Based on experimental data and on clinical results in RA and psoriasis, we believe that the recent humanized anti-CD6specific mAb T1h may act as a regulator of the immunological response in addition to its function as an anti-T-and -B cell agent.
\end{abstract}

\section{Introduction}

The past few years have witnessed increasing interest in the possibility that B lymphocytes are cast with a leading role in the play of autoimmunity. Treatment with B celldepleting agents has thus become the logics. Among these is the anti-CD6 antibodies (Abs), because CD6 is harboured, not only by all $\mathrm{T}$ cells, but also by some $\mathrm{B}$ cells. The earliest successes of anti-CD6 Abs in autoimmune diseases [1-3] were obtained in the treatment of rheumatoid arthritis (RA), psoriasis, and multiple sclerosis (MS) (Table 1). In spite of such promising results, the investigators had to give up $[4,5]$ due to the murine origin of their monoclonal Abs (mAbs). There was thus a need for humanized anti-CD6 mAb. This task was accomplished by mutagenesis in 2003 using the murine anti-CD6 single scavenger receptor cystein-rich (SRCR) domain 1 , ior T1 $[6,7]$. The resulting humanized anti-CD6 $\mathrm{mAb}$ was termed T1h, and evaluated in RA and psoriasis. The preliminary results in active RA [8] revealed that the combination of T1h, with methotrexate resulted in a long-term remission with a significative reduction of swollen and tender joints. The question, therefore, arises as to how the anti-CD6 T1h mAb work? First, one might argue that anti-CD6 Ab should target the T cells, as well. Were that to be the case, a T-cell depletion should be elicited such was not the case. Second, it may block interactions between CD6 and the activated leukocyte cell adhesion molecule (ALCAM). However, in vivo experiments and in vitro competition assays have cast doubt on this possibility. By self-definition, it is important to define the rationale for using anti-CD6 $\mathrm{mAb}$ in autoimmune diseases. The present review summarizes our knowledge regarding CD6, its functions, and the different anti-CD6 mAbs that have been developed and tested.

\section{CD6 from the Gene to the Protein}

2.1. cd6 Gene. The gene for $c d 6$, a T-cell differentiation antigen (Ag) maps to chromosome 11 at position 11q13.1, spans more than $25-\mathrm{kb}$ adjacently, and adjoins the $c d 5$ gene within $200-\mathrm{kb}$ telomeric to $c d 20$ in human [9]. In mice and chicken, the $c d 6$ gene is present on chromosome 19 and 5, respectively, $[10,11]$. Phylogenetic analysis supports 
TABLE 1: Anti-CD6 and clinical studies.

\begin{tabular}{|c|c|c|c|}
\hline Clone & Diseases & Effect & Author \\
\hline Ior T1 & $\begin{array}{l}\text { T cell lymphoma, } \\
\text { Psoriasis }\end{array}$ & Clinical improvement & {$[1]$} \\
\hline $\begin{array}{l}\text { Ior T1- } \\
\text { 99Tcm }\end{array}$ & Rheumatoid arthritis & Clinical improvement & {$[2]$} \\
\hline $\mathrm{T} 12$ & Multiple sclerosis & $\mathrm{T}$ cell depletion & {$[3]$} \\
\hline T12 & $\begin{array}{l}\text { BM transplantation in } \\
\text { SCID patient }\end{array}$ & $\begin{array}{l}\text { Prevent acute GvH } \\
\text { disease }\end{array}$ & {$[4]$} \\
\hline $\mathrm{T} 12$ & $\begin{array}{l}\text { Allogeneic BM } \\
\text { transplantation }\end{array}$ & T cell elimination & {$[5]$} \\
\hline
\end{tabular}

GvH disease: graft-versus-host disease; BM: bone marrow, IV: intravenous; SCID: severe combined immunodeficiency.

the concept that $c d 6$ and $c d 5$ have emerged from duplication of a common ancestor, probably before the separation of mammalian/birds and amphibian 200-300 million years ago (Figure 1). Interestingly, in humans, but not in mice, an endogenous retrovirus type $\mathrm{E}$ is inserted between $c d 6$ and $c d 5$ genes, and serves as an alternative gene promoter for $c d 5$. The influence on $c d 6$ is unknown $[12,13]$.

A minimal $c d 6$ promoter has been recently described at positions -506/-146 from the start codon ATG (+1) [14]. Mutational analysis of the promoter and characterization of related transcription factors (TFs) have identified Ets- 1 and RUNX1/3 as $c d 6$ regulators. Likewise, $c d 5$ gene is positively regulated by Ets- 1 and NFAT, and negatively regulated by E47 [15-17]. The inhibitory effect of E47 on the expression of CD6 has never been described, even though the $c d 6$ promoter contains an E-box-binding domain at position -273 . In addition, $c d 6$ promoter is regulated at the epigenetic level through methylation of its $15 \mathrm{CpG}$ motifs between positions $-300 /+1$. As observed by treating cloned human $T$ cells with the DNA methylation inhibitor 5-azacytidine [18].

RNase protection assay and 5'RACE RT-PCR show multiple transcriptional start sites in accordance with the absence of TATA box in the $5^{\prime}$ flanking region of $c d 6$ [14]. In humans, exon 1 contains the start codon and exon 13 contain the stop codon. In between, a nucleotide-long-related open reading frame corresponds to a 668 -amino acid (aa) protein. Exons 1 and 2 encode the 24-aa signal sequence, exons 3 through 5 encode each a 101/117-aa SRCR domain, exon 6 encodes a 22-aa spacer that separates the SRCR-D3 from the exon 7-encoded 26-aa transmembrane domain, while exons 8 through 13 encode the cytoplasmic domain of CD6 (Figure 2). Analysis of single-nucleotide polymorphisms (SNPs) in the $c d 6$ locus has unveiled association between MS and the SNP rs17824933 in exon $1[19,20]$. Besides this wellknown SNP which is associated with CD6 lower expression [21], another 8 nonsynonymous SNPs characterize the coding region but their effects are unknown.

2.2. CD6 Transcripts. Hematopoietic precursors thymocytes, mature T and NK cells, a subset of normal B lymphocytes and most of those from lymphocytic chronic leukemia (CLL) transcribe mRNAs for CD6. In B cells, CD6 expression predominates in mature $\mathrm{B}$ cells (usually in association with
CD5) which make IgM, but do not isotype switch [22]. CD6 mRNA is also detected in various brain regions, most notably in basal ganglia and cortex cerebellum [23, 24].

Northern blot detects a $3-\mathrm{kb}$ band corresponding to CD6 mRNA in T lymphocytes and brain cells. Its intensity augments after exposure to phorbol myristic acetate (PMA), a protein kinase $\mathrm{C}$ activator (PKC), or incubation with phytohaemagglutinin (PHA). Controversy persists over the influence of the B-cell Ag receptor (BCR) engagement on CD6 expression. Some authors, but not all, observed an induction of CD6 upon anti-IgM or superantigen Staphylococcus aureus Cowan I stimulation [22, 25].

Among the mRNAs for CD6, several alternative splices have been identified by RT-PCR, and confirmed by sequencing (Figure 2): one lacking exon $5(\mathrm{CD} 6 \Delta \mathrm{D} 3)$ in T cells, and at least four isoforms lacking exon(s) for the cytoplasmic domain of CD6: $\Delta 8, \Delta 8-9, \Delta 8 / \Delta 12$ or $\Delta 9 / \Delta 12$ in CLL [26]. An exon 9-lacking splicoform has also been described in mice $[27,28]$. CD $6 \Delta \mathrm{D} 3$ expression is upregulated throughout the maturation of thymocytes, and following stimulation with PHA [29]. However, the full-length CD6-encoding cDNA predominate in resting and activated cells.

2.3. CD6 Protein. Of the $105 \mathrm{kDa}$-molecular weight (MW) of glycoprotein, $35 \mathrm{kDa}$ are accounted for by polysaccharides. This heavy glycosylation is rendered possible by eight putative sites for $\mathrm{N}$-glycosylation and two putative sites for $O$-glycosylation in the extracellular part of the molecule. In addition, when lymphocytes are activated by PMA or by fetal calf serum, CD6 serine, threonine, and tyrosine (Y) residues are hyperphosphorylated and the MW of the related band increased from 105 to $130 \mathrm{kDa}$ [30]. Comparison of the CD6 SRCR domains between human and mouse shows 54\% aa identity for SRCR-D1, $84 \%$ for SRCR-D2, and $81 \%$ for SRCR-D3 [7], and 69\% for the transmembrane domain [28].

The 244-aa cytoplasmic tail of CD6 harbors nine threonine and 32 serine residues. Two proteins, SLP-76 and synthenin-1, may be physically associated with Y662 of human CD6 $[31,32]$. Of note, SLP-76 that activate PKC and MAPK pathways requires Y662 phosphorylation to bind CD6 [31, 33]. Synthenin-1 is important in protein trafficking, cell adhesion, and activation of Sox 4 and eIF5A TFs. In rat, CD6 associates with different protein tyrosine kinases, including Lck, Fyn, Zap-70, and Itk [34].

In $\mathrm{T}$ and $\mathrm{B}$ cells, interactions with kinases are reinforced when aa are Y phosphorylated upon PMA or, anti-CD3 stimulation, with, but also without, CD2 or CD4 crosslinking $[35,36]$. Ligation of CD6 with anti-CD6 $\mathrm{mAb}$ on both normal and leukemic human $\mathrm{T}$ cells triggers off the activation of the MAPK cascade with phosphorylation of Erk1/2, p38 and JNK [37]. However, cross-linking the anti$\mathrm{CD} 6 \mathrm{mAb}$ is required to launch the MAPK pathways.

\section{Biological Functions}

3.1. CD6-Positive and CD6-Negative Cells. There are no CD6 knockout or CD6-knockin mice, yet CD6-positive cells and CD6-negative cells were compared in $\mathrm{T}$ and $\mathrm{B}$ cells. 

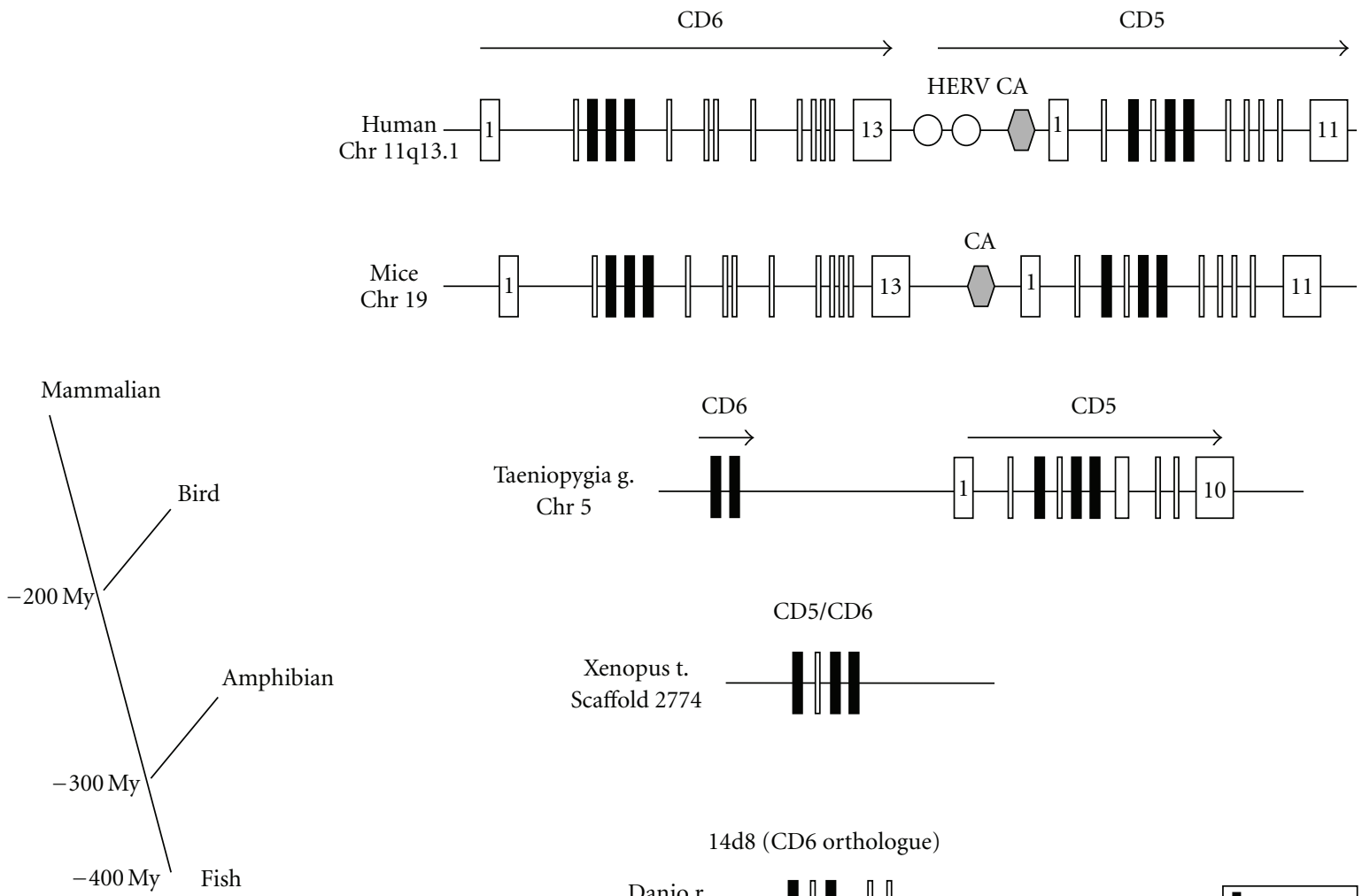

$14 \mathrm{~d} 8$ (CD6 orthologue)

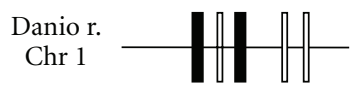

SRCR

FIGURE 1: CD6 and CD5 genes map to contiguous regions in mammalian and birds and are supposed to have arisen for implication of a common ancestral gene. CD6 is orthologue to the amphibian protein CD5/CD6 and the fish protein 14d8. Data has been taken from the genome database (http://www.ensembl.org/) and from previously published results $[11,13]$. Black boxes represent the exons encoding the extracellular SRCR domains. First and last exons are depicted when known. Legend: HERV human endogenous retrovirus; CA: microsatellite repeat, My: million year.

In $\mathrm{T}$ cells, CD6-positive lymphocytes proliferate more than CD6-negative lymphocytes in the presence of stimulation by allo-Ag presenting cells (APCs) [38]. T- and B-cell proliferation in response to mitogens is similar in CD6positive cells and in CD6-negative cells $[22,38]$. The latter $\mathrm{B}$ cells, in the presence of $\mathrm{T}$ cells and PMA, produce high amount of $\operatorname{IgM}$ and $\operatorname{IgG}$, whereas CD6-positive B cells produce little IgM, and do not make IgG [22].

\subsection{Transligation}

3.2.1. Main CD6 Ligand. ALCAM belongs to the immunoglobulin (Ig) cell adhesion molecule superfamily. It is expressed on bone marrow (BM) stromal cells, thymic epithelial cells, activated $\mathrm{T}$ and $\mathrm{B}$ cells, monocytes, dendritic cells, synovial fibroblasts, keratinocytes, and mesangial stem cells. ALCAM was identified as a ligand of CD6 [39, 40]. ALCAM expression is tightly regulated, and indeed mitogenactivated peripheral blood mononuclear cells (PBMCs) express ALCAM for 24 to $48 \mathrm{~h}$, but not thereafter [41].

The extracellular region of ALCAM consists of five extracellular Ig domains (D1-D5). The two NH2-terminal domains are related to variable (V)-type and the three proximal domains to constant $(\mathrm{C})$-type Ig domains. The $\mathrm{N}$ - terminal domain of ALCAM interacts with the conserved SRCR-D3 of CD6, while the C-proximal domains oligomerize ALCAM. The CD6 binding domain for ALCAM is highly conserved, explaining the cross-species CD6/ALCAM interaction between humans, mice, and chickens. This is also the reason why it is so difficult to mount an $\mathrm{Ab}$ response against the CD6 binding site [41]. Like most other leukocyte membrane interactions, the heterotypic ALCAMCD6 interaction is of low affinity, albeit 10- to 100-fold higher than the homotypic ALCAM-ALCAM interaction [42]. Binding studies with CD6 fusion proteins has revealed that CD6-SRCR-D2 (exon 4) and CD6 spacer domain (exon 6) are important to stabilize the interaction between CD6SRCR-D3 and ALCAM [43]. Mutagenesis analysis has shown that three residues in the $C$-terminal region of CD6-SRCRD3 and nine residues in the ALCAM-D1 domain are involved in the binding/interaction CD6/ALCAM [44].

The binding of CD6 to ALCAM is dominant for CD34 ${ }^{+}$ hematopoietic progenitor binding to BM stromal cells [45], thymocyte binding to thymic epithelial cells $[39,40]$, and T-cell-dependent proliferation [46]. In pathological settings, supplemental functions have been ascribed to the complex CD6/ALCAM. First, CD4 ${ }^{+}$-T-cell transmigration into the central nervous system is related to CD6/ALCAM interaction 


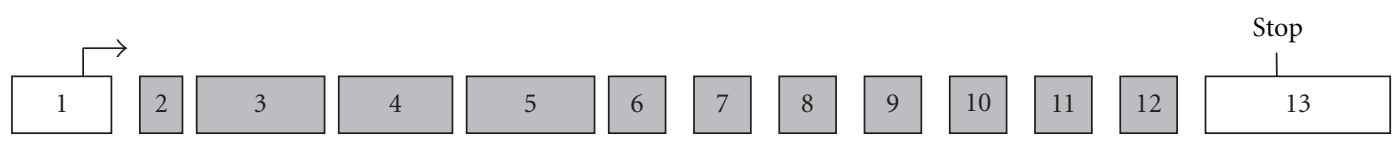

(a) Human CD6 gene

\begin{tabular}{|c|c|c|c|c|c|c|c|c|c|c|c|c|c|}
\hline CD6a & 1 & 2 & 3 & 4 & 5 & 6 & 7 & 8 & 9 & 10 & 11 & 12 & 13 \\
\hline CD6b & 1 & 2 & 3 & 4 & 5 & 6 & 7 & & 9 & \begin{tabular}{|l|}
10 \\
\end{tabular} & \begin{tabular}{|l|}
11 \\
\end{tabular} & 12 & 13 \\
\hline CD6c & 1 & 2 & 3 & 4 & 5 & 6 & 7 & & & 10 & \begin{tabular}{|l|}
11 \\
\end{tabular} & 12 & 13 \\
\hline CD6d & 1 & 2 & 3 & 4 & 5 & 6 & 7 & & 9 & 10 & \begin{tabular}{|l|}
11 \\
\end{tabular} & & 13 \\
\hline CD6e & 1 & 2 & 3 & 4 & 5 & 6 & 7 & 8 & & \begin{tabular}{|l|}
10 \\
\end{tabular} & \begin{tabular}{|l|l|}
11 \\
\end{tabular} & & 13 \\
\hline CD6f & 1 & 2 & 3 & 4 & 5 & 6 & 7 & 8 & & \begin{tabular}{|l|}
10 \\
\end{tabular} & \begin{tabular}{|l|}
11 \\
\end{tabular} & 12 & 13 \\
\hline CD6 $\Delta 3$ & 1 & 2 & 3 & 4 & & 6 & 7 & 8 & 9 & \begin{tabular}{|l|}
10 \\
\end{tabular} & \begin{tabular}{|l|}
11 \\
\end{tabular} & 12 & 13 \\
\hline
\end{tabular}

(b) mRNA and alternative splicing
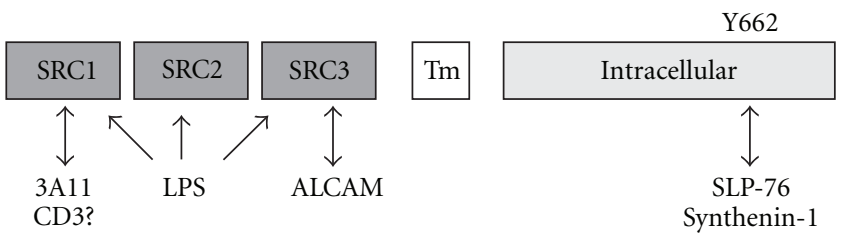

(c) CD6 protein

FIgURE 2: Human CD6 transcripts. (a) Diagram of the human CD6 gene exons which are depicted as boxes numbered from 1 to 13. (b) Representation of the different CD6 isoforms. (c) Scheme of the CD6 protein. The localization of the different binding domains is indicated.

at the border between blood and brain [47]. Second, ALCAM overexpression entrances the lymphocyte recruitment to inflammatory sites, including RA synovium, SS exocrine glands, MS brain, and microenvironment of selected cancers [47-50].

3.2.2. Accessory Ligands for CD6. The list of CD6 ligands is extremely long, based on the observation that CD6 fusion protein immunoprecipitate from a human epithelial cell live not only with ALCAM, but also with a $90-\mathrm{kDa}$ and a $45-\mathrm{kDa}$ proteins [51]. Another clue to additional ligand(s) for CD6 is that the binding of $\mathrm{T}$ cells to epithelial cells cannot be totally blocked by anti-CD166 Ab and by anti-CD6 SRCR-D3 Ab [52].

Following activation with IFN- $\gamma$ a $130-\mathrm{kDa}$ protein designated 3A11 arises on synovial fibroblasts, thymic fibroblast, and keratinocytes [52-54]. The interaction could be abrogated by a CD6 fusion protein or an anti-CD6 SRCRD1 Ab suggesting that CD6 domain SRCR-D1 recognizes alternative ligands.

3.2.3. Pathogen Recognition. The Lozano's group has recently reported on the binding of CD6 and CD5 to pathogenassociated molecular patterns $[55,56]$. Catching of pathogen by CD6 is dose dependent, saturable, facilitated by calcium, and achieved by the three SRCR domains. Microbes induce signaling with MAPK/Erk activation and cytokine release. This Toll-like receptor-independent process requires the integrity of the cytoplasmic domain as demonstrated with CD5. Interestingly, soluble CD6 and CD5 have been detected in normal human sera, and their levels found to be increased in autoimmune diseases, thus suggesting a feedback loop to reduce direct lymphocyte activation by pathogens $[57,58]$.

\subsection{Cis Ligation}

3.3.1. CD6-CD3 Interactions and Immunological Synapse. The junction between a T lymphocyte and an APC is designated as immunological synapse (IS) and assigned to an active mechanism. First, T-cell Ag receptor (TCR) ligands and costimulatory molecules are engaged in an external ring of the nascent IS, translocated into the central cluster, and fixed in the heart of the IS. Finally, the IS consists of the central supramolecular activation cluster (cSMAC) enriched in TCR/CD3 complexes, CD4/CD8/CD2/CD5 costimulatory molecules, and kinases (PKC, Lck and Fyn), and surrounded by a supramolecular activation clusters (pSMAC) including LFA- 1 and talin.

The fact that CD6 exists both in pSMAC and in cSMAC suggests the possibility of two functions, each being related to its location $[29,59,60]$. At the PSMAC, CD6 binds to ALCAM. This is stable, long lasting and involved in the contact initiation between T cells and APCs. Then blocking CD6-ALCAM interaction reduces significantly T-cell/APC contact and impairs the T-cell proliferation. This could be achieved with anti-CD6-SRCR-D3 Ab or ALCAM-blocking $\mathrm{Ab}$. In addition, when the cells express an alternative isoform of CD6, CD6 $\triangle \mathrm{D} 3$, devoid of ALCAM binding domain, the contact of lymphocytes with APC is lost [29]. At the cSMAC, CD6 is physically associated with the TCR/CD3 complex, 
and, as such, participates in the proliferation of T cells. Since T1h related anti-CD6-SRCR-D1 Ab are able to inhibit T-cell proliferation without affecting T-cell/APC contact it could be postulated that this interaction involved the SRCR-D1 part of CD6.

3.3.2. CD6 and CD5 Association. Confocal microscopy, coupled with the FRET technology [61], establishes that $12 \%$ of the CD6 molecules are associated with CD5 molecules in resting $\mathrm{T}$ cells. Upon activation, this association is reinforced and the CD6-CD5 complexes migrate to the IS where they colocalize with TCR/CD3 within the cSMAC. Of note, complexes of cross-linked CD5 and CD6 are internalized, and, by doing so, confirm their physical link.

Interactions between CD6 and CD5 proceed through their extracellular domains given that, despite truncation of its intracellular tail, CD5 keeps its ability to bind CD6. Which CD6 extracellular domain is involved is currently unknown. The CD5-CD6 interaction is not unique, since CD5 SRCR-D2 interact with the BCR [62], CD5 SRCRD3 interferes with itself [63] and interacts with CD2 [64]. Interestingly, when CD6 and CD5 are physically associated, CD6 is phosphorylated on its Y629 and CD5 on its Y429, suggesting that their association contributes to TCR- or BCR-independent activation. This was demonstrated in rat $\mathrm{T}$ cells by immunoprecipitation where CD5 was associated with hyperphosphorylated 130-kDa CD6, and CD6 with hyperphosphorylated CD5 [65].

Over the thymic maturation, the expression CD6, that of CD5 (and thereby their interactions) are tightly regulated, and contributes to the thymocyte selection. Immature double-negative $\mathrm{CD}^{-} \mathrm{CD}^{-}$thymocytes express $\mathrm{CD} 6$ and low levels of $\mathrm{CD} 5$, at immature double-positive $\mathrm{CD} 4^{+} \mathrm{CD} 8^{+}$ stage CD6 expression is stable and CD5 is increased, finally at single-positive $\mathrm{CD}^{+}$or $\mathrm{CD}^{+}$stages both molecules are highly expressed $[66,67]$. When compared to singlepositive thymocytes, cell surface expression on resting peripheral blood T cells is lower for CD6 and similar for CD5.

Within the B lymphocytes, the CD6-expressing cells overlap, but not entirely, with the CD5-expressing cells [68]. CD5-expressing B cell, designated B1 cells, as opposed to conventional CD5-nonexpressing B2 cells, produce polyspecific Abs and, therefore, constitute the main source of natural Abs. In fact, the CD6 molecule acts as a positive regulator of the BCR while CD5 is a negative regulator.

\section{Anti-CD6 Immunotherapy}

4.1. Anti-CD6 Monoclonal Abs. Different anti-CD6 mAbs have been raised, mainly against the first and third SRCR domains of CD6. Four main epitopes are described in the SRCR-D1 [69]. Briefly, anti-CD6-SRCR-D1 mAbs hinder autoreactive and nonautoreactive T-cell proliferation while anti-CD6-SRCR-D3 mAb prevents the adhesion and Agdependent activation of lymphocytes via its interaction with ALCAM (Table 2 and Figure 3).

Ligation of the CD6 cell surface molecule by cross-linking an anti-SRCR-D1 mAb mimics the CD6-CD166 interaction
TABLE 2: Anti-CD6 SRCR-D1 mAbs and functional effects.

\begin{tabular}{llcc}
\hline Clone & Functional response & $\begin{array}{c}\text { Cross- } \\
\text { link }\end{array}$ & Author \\
\hline $\begin{array}{l}\text { BLTP6a, UMCD6 and } \\
\text { MT502 }\end{array}$ & $\begin{array}{l}\text { Block T-cell Ag } \\
\text { dependant activation }\end{array}$ & No & {$[18]$} \\
161.8 & $\begin{array}{l}\text { Induces Erk1/2 } \\
\text { activation }\end{array}$ & Yes & {$[37]$} \\
IorT1, 2H1, T12, 6D3, & $\begin{array}{l}\text { Enhance anti-CD3, } \\
\text { anti-CD28 and PMA T } \\
\text { cell proliferation }\end{array}$ & Yes & {$[70,71]$} \\
Dako-CD6 & $\begin{array}{l}\text { Protects B-CLL from } \\
\text { anti-IgM apoptosis } \\
\text { Blocks }\end{array}$ & Yes & {$[25]$} \\
Ior T1 & $\begin{array}{l}\text { T-cell/keratinocyte } \\
\text { interaction }\end{array}$ & No & {$[18]$} \\
UMCD6 & & & \\
\hline
\end{tabular}

and delivers a direct signal by activating $\operatorname{MAPK}[37,55]$. T-cell proliferation could be achieved or amplified when ligation of the CD6 molecule is associated with a second signal mediated by the ligation of CD3, CD28, or with PMA [69]. This proliferation is IL-2 dependent.

In B cells, CD6 ligation was not found to induce the proliferative response of CLL but to protect from anti-IgMmediated apoptosis through bcl-2 induction [25]. CLL Bcell spontaneous apoptosis is not affected by CD6 crosslinking.

4.2. Anti-CD6 and Clinical Studies. The murine IgM antiT12/CD6 mAb has been used experimentally in vivo as an anti-T-cell agent in MS, leukaemia, in acute graft-versushost $\mathrm{GvH}$ disease, and in acute renal transplant rejection [3, 4, 72]. However, circulating CD6-positive T cells disappear completely the first week, the appearance of blocking human anti-mouse IgM in the serum by $78 \%$ of the patients, seven days after infusion, together with allergic reactions limits the efficiency of the mAb. In addition, the anti-T12/CD6 mAb associated with rabbit complement was also used ex vivo for removing $\mathrm{T}$ cells from the donor BM, as an attempt to reduce the incidence of acute and chronic $\mathrm{GvH}$ disease. These allogeneic CD6-depleted BM transplantations have been used successfully in patients with hematologic malignancies and severe combined immunodeficiency [73, 74]. After BM transplantation, NK cells are reconstituted early, and $\mathrm{T}$ cells are detected after four to eight weeks including T-cell functional abnormalities and a significant fraction of CD6nonexpressing $\mathrm{T}$ cells [75]. A decade ago, transplantation of anti-T12/CD6 T-cell-depleted BM was supplanted by the selection of stem cells CD34 ${ }^{+}$.

CD6 $\mathrm{mAb}$ ior $\mathrm{T} 1$ (IgG2a,k) was raised in BALB/c mice immunized with PBMCs from a patient with Sezary's syndrome $[6,7]$. Ior $\mathrm{T} 1 \mathrm{mAb}$, another anti-CD6 SRCRD1 mAb, has been used with success in cutaneous T-cell lymphoma and in a patient with psoriasis [1]. A technetium99m-labeled ior T1 mAb was tested in a phase II clinical trial in RA demonstrating a link between the concentration used and the clinical improvement [2]. 


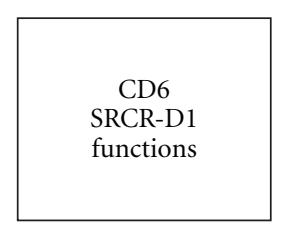

$$
\begin{gathered}
\text { Ligands: } \\
\text { 3A11, CD3? }
\end{gathered}
$$
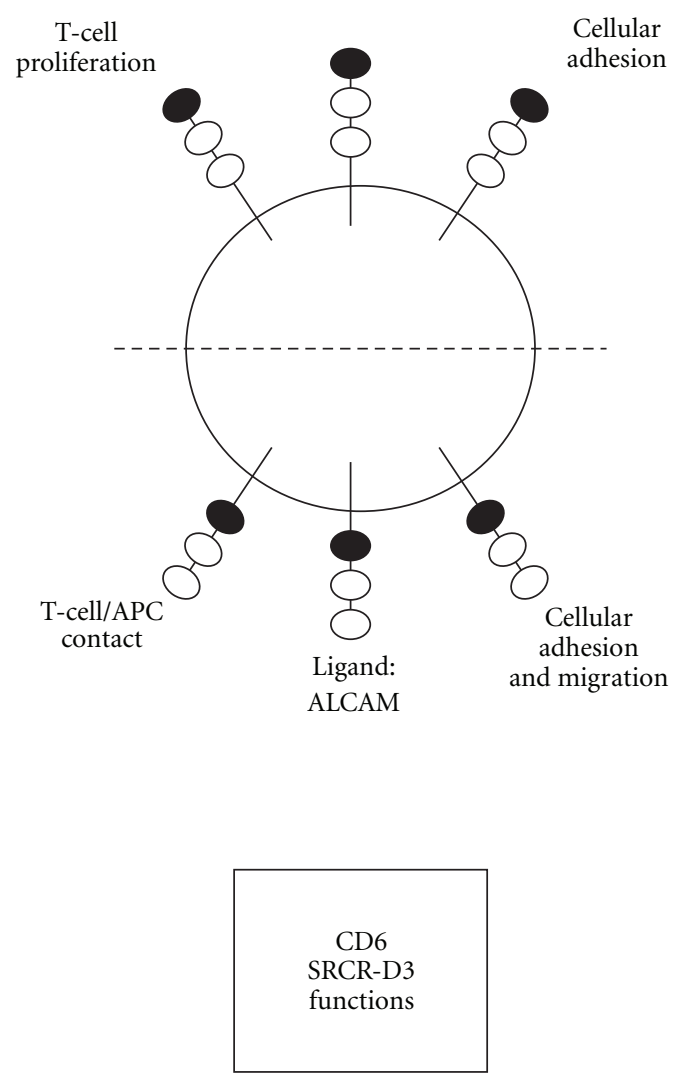

Figure 3: CD6 functions according to the CD6 scavenger receptor cystein-rich (SRCR) domain involved.

4.3. Humanized Anti-CD6 Monoclonal Ab. To reduce its immunogenicity, ior $\mathrm{T} 1 \mathrm{mAb}$ has been genetically engineered to progressively replace murine content with the human counterparts. In the first step, a chimeric human-mouse IgG was generated by exchanging corresponding heavy chain $\mathrm{C}$ domains between the human IgG1 and the murine IgG2a. In the second step, the two homologous mouse and human $\mathrm{V}$ region sequences were compared and $\mathrm{Ag}$ sequences of $T$ cells were analyzed. In the third step, 11 aa present in the $\mathrm{V}$ region were subjected to point mutations to make them human and/or to modify amphiphatic motifs [6]. The resulting recombinant $\mathrm{Ab}(\mathrm{T} 1 \mathrm{~h})$ retained its $\mathrm{Ag}$-binding affinity and was less immunogenic than the murine original $[6,7]$. Humanized anti-CD6 T1h recognizes a conformational epitope independent of the CD6 $\mathrm{N}$-glycosylation of SRCR-D1. As suspected, it does not block CD6-ALCAM interactions suggesting that $\mathrm{T} 1 \mathrm{~h}$ could not inhibit ALCAMrelated T-cell activation and prevent $\mathrm{T}$-cell migration.

\section{Conclusions}

CD6 SRCR-D1 contributes to lymphocyte proliferation, adhesion and survival process. Indeed, the humanized antiCD6 SRCR-D1 clone T1h which does not interfere with the CD6-ALCAM interactions may have therapeutic implications in oncology, transplantation, and autoimmunity. The recent data obtained with soluble recombinant CD6 in an experimental model of septic stock support this model.

\section{Acknowledgments}

This work was supported by grants from the Ligue Contre le Cancer (comités 22, 29, and 56), the Conseil Régional de Bretagne, the Conseil Général du Finistère, and the French Ministry for Education and Research. The authors are grateful to Simone Forest for her secretarial assistance.

\section{References}

[1] E. Montero, L. Falcon, Y. Morera, J. Delgado, J. F. Amador, and R. Perez, "CD6 molecule may be important in the pathological mechanisms of lymphocytes adhesion to human skin in psoriasis and ior $\mathrm{t} 1 \mathrm{MAb}$ a possible new approach to treat this disease," Autoimmunity, vol. 29, pp. 155-156, 1999.

[2] E. Montero, G. Reyes, M. Guibert et al., "Immunodiagnosis and therapeutic immunosuppression in rheumatoid arthritis with ior t1 (anti-CD6) monoclonal antibody," Arthritis Research \& Therapy, vol. 4, article 38, 2002.

[3] D. A. Hafler, R. J. Fallis, and D. M. Dawson, "Immunologic responses of progressive multiple sclerosis patients treated with an anti-T-cell monoclonal antibody, anti-T12," Neurology, vol. 36, no. 6, pp. 777-784, 1986.

[4] E. L. Reinherz, R. Geha, J. M. Rappeport et al., "Reconstitution after transplantation with Tlymphocyte-depleted HLA haplotype-mismatched bone marrow for severe combined immunodeficiency," Proceedings of the National Academy of Sciences of the United States of America, vol. 79, pp. 6047-6051, 1982.

[5] D. Resnick, A. Pearson, and M. Krieger, "The SRCR superfamily: a family reminiscent of the Ig superfamily," Trends in Biochemical Sciences, vol. 19, no. 1, pp. 5-8, 1994.

[6] L. Roque-Navarro, C. Mateo, J. Lombardero et al., "Humanization of predicted T-cell epitopes reduces the immunogenicity of chimeric antibodies: new evidence supporting a simple method," Hybridoma and Hybridomics, vol. 22, no. 4, pp. 245257, 2003.

[7] R. Alonso, V. Huerta, J. De Leon et al., "Towards the definition of a chimpanzee and human conserved CD6 domain 1 epitope recognized by T1 monoclonal antibody," Hybridoma, vol. 27, no. 4, pp. 291-301, 2008.

[8] E. Montero, R. Casaco, Z. Muzzora, R. Alonso-Ramirez, and R. Parey, "Pharmaceutical composition, comprising an antiCD6 mAb used in the diagnosis and treatment of rheumatoid arthritis," EP2119452, 2009.

[9] O. Lecomte, J. B. Bock, B. W. Birren, D. Vollrath, and J. R. Parnes, "Molecular linkage of the mouse CD5 and CD6 genes," Immunogenetics, vol. 44, no. 5, pp. 385-390, 1996.

[10] O. Padilla, J. Calvo, J. M. Vilà et al., "Genomic organization of the human CD5 gene," Immunogenetics, vol. 51, no. 12, pp. 993-1001, 2000. 
[11] R. Koskinen, J. Salomonsen, M. Goodchild, N. Bumstead, Y. Boyd, and O. Vainio, "Structure and chromosomal localization of chicken CD5," Scandinavian Journal of Immunology, vol. 54, no. 1-2, pp. 141-145, 2001.

[12] Y. Renaudineau, S. Hillion, A. Saraux, R. A. Mageed, and P. Youinou, "An alternative exon 1 of the CD5 gene regulates CD5 expression in human B lymphocytes," Blood, vol. 106, no. 8, pp. 2781-2789, 2005.

[13] Y. Renaudineau, S. Vallet, C. Le Dantec, S. Hillion, A. Saraux, and P. Youinou, "Characterization of the human CD5 endogenous retrovirus-E in B lymphocytes," Genes and Immunity, vol. 6, no. 8, pp. 663-671, 2005.

[14] M. Arman, N. Aguilera-Montilla, V. Mas et al., "The human CD6 gene is transcriptionally regulated by RUNX and Ets transcription factors in T cells," Molecular Immunology, vol. 46, no. 11-12, pp. 2226-2235, 2009.

[15] M. Arman, J. Calvo, M. E. Trojanowska et al., "Transcriptional regulation of human CD5: important role of Ets transcription factors in CD5 expression in T cells," Journal of Immunology, vol. 172, no. 12, pp. 7519-7529, 2004.

[16] R. Berland and H. H. Wortis, "An NFAT-dependent enhancer is necessary for anti-IgM-mediated induction of murine CD5 expression in primary splenic B cells," Journal of Immunology, vol. 161, no. 1, pp. 277-285, 1998.

[17] Y. Yang, C. H. Contag, D. Felsher et al., "The E47 transcription factor negatively regulates CD5 expression during thymocyte development," Proceedings of the National Academy of Sciences of the United States of America, vol. 101, no. 11, pp. 3898-3902, 2004.

[18] N. G. Singer, B. C. Richardson, D. Powers et al., "Role of the CD6 glycoprolein in antigen-specific and autoreactive responses of cloned human T lymphocytes," Immunology, vol. 88, no. 4, pp. 537-543, 1996.

[19] P. L. De Jager, X. Jia, J. Wang et al., "Meta-analysis of genome scans and replication identify CD6, IRF8 and TNFRSF1A as new multiple sclerosis susceptibility loci," Nature Genetics, vol. 41, no. 7, pp. 776-782, 2009.

[20] B. Swaminathan, F. Matesanz, M. L. Cavanillas et al., "Validation of the CD6 and TNFRSF1A loci as risk factors for multiple sclerosis in Spain," Journal of Neuroimmunology, vol. 223, no. 1-2, pp. 100-103, 2010.

[21] G. A. Heap, J. H. M. Yang, K. Downes et al., "Genome-wide analysis of allelic expression imbalance in human primary cells by high-throughput transcriptome resequencing," Human Molecular Genetics, vol. 19, no. 1, pp. 122-134, 2009.

[22] N. Endres, G. Riethmueller, and E. P. Rieber, "Functional characterization of a novel B-cell subset defined by the CD6 antigen," in Leukocyte Typing IV, W. Knapp, B. Doerken, W. R. Gilks et al., Eds., pp. 340-351, Oxford University Press, Oxford, UK, 1989.

[23] B. Mayer, I. Funke, B. Seed, G. Riethmuller, and E. Weiss, "Expression of the CD6 T lymphocyte differentiation antigen in normal human brain," Journal of Neuroimmunology, vol. 29, no. 1-3, pp. 193-202, 1990.

[24] A. Konno, J. S. Ahn, H. Kitamura et al., "Tissue distribution of CD6 and CD6 ligand in cattle: expression of the CD6 ligand (CD166) in the autonomic nervous system of cattle and the human," Journal of Leukocyte Biology, vol. 69, no. 6, pp. 944950, 2001.

[25] L. M. Osorio, A. De Santiago, M. Aguilar-Santelises, H. Mellstedt, and M. Jondal, "CD6 ligation modulates the Bcl2/Bax ratio and protects chronic lymphocytic leukemia B cells from apoptosis induced by anti-IgM," Blood, vol. 89, no. 8, pp. 2833-2841, 1997.
[26] M. A. Bowen, G. S. Whitney, M. Neubauer et al., "Structure and chromosomal location of the human CD6 gene: detection of five human CD6 isoforms," Journal of Immunology, vol. 158, no. 3, pp. 1149-1156, 1997.

[27] G. Whitney, M. Bowen, M. Neubauer, and A. Aruffo, "Cloning and characterization of murine CD6," Molecular Immunology, vol. 32, no. 1, pp. 89-92, 1995.

[28] W. H. Robinson, S. S. Prohaska, J. C. Santoro, H. L. Robinson, and J. R. Parnes, "Identification of a mouse protein homologous to the human CD6 T cell surface protein and sequence of the corresponding cDNA," Journal of Immunology, vol. 155, no. 10, pp. 4739-4748, 1995.

[29] M. A. A. Castro, M. I. Oliveira, R. J. Nunes et al., "Extracellular isoforms of CD6 generated by alternative splicing regulate targeting of CD6 to the immunological synapse," Journal of Immunology, vol. 178, no. 7, pp. 4351-4361, 2007.

[30] L. Cardenas, A. C. Carrera, E. Yague, R. Pulido, F. Sanchez-Madrid, and M. O. De Landazuri, "Phosphorylationdephosphorylation of the CD6 glycoprotein renders two isoforms of 130 and 105 kilodaltons. Effect of serum and protein kinase C activators," Journal of Immunology, vol. 145, no. 5, pp. 1450-1455, 1990.

[31] N. J. Hassan, S. J. Simmonds, N. G. Clarkson et al., "CD6 regulates T-cell responses through activation-dependent recruitment of the positive regulator SLP-76," Molecular and Cellular Biology, vol. 26, no. 17, pp. 6727-6738, 2006.

[32] I. Gimferrer, A. Ibáñez, M. Farnós et al., "The lymphocyte receptor CD6 interacts with syntenin-1, a scaffolding protein containing PDZ domains," Journal of Immunology, vol. 175, no. 3, pp. 1406-1414, 2005.

[33] J. N. Wu and G. A. Koretzky, "The SLP-76 family of adapter proteins," Seminars in Immunology, vol. 16, no. 6, pp. 379-393, 2004.

[34] M. A. A. Castro, R. J. Nunes, M. I. Oliveira et al., "OX52 is the rat homologue of CD6: evidence for an effector function in the regulation of CD5 phosphorylation," Journal of Leukocyte Biology, vol. 73, no. 1, pp. 183-190, 2003.

[35] S. Wee, G. L. Schieven, J. M. Kirihara, T. T. Tsu, J. A. Ledbetter, and A. Aruffo, "Tyrosine phosphorylation of CD6 by stimulation of CD3: augmentation by the CD4 and CD2 coreceptors," Journal of Experimental Medicine, vol. 177, no. 1, pp. 219-223, 1993.

[36] J. Kobarg, G. S. Whitney, D. Palmer, A. Aruffo, and M. A. Bowen, "Analysis of the tyrosine phosphorylation and calcium fluxing of human CD6 isoforms with different cytoplasmatic domains," European Journal of Immunology, vol. 27, no. 11, pp. 2971-2980, 1997.

[37] A. Ibáñez, M. R. Sarrias, M. Farnós et al., "Mitogen-activated protein kinase pathway activation by the CD6 lymphocyte surface receptor," Journal of Immunology, vol. 177, no. 2, pp. 1152-1159, 2006.

[38] R. A. Rasmussen, S. L. Counts, J. F. Daley, and S. F. Schlossman, "Isolation and characterization of CD6 T cells from peripheral blood," Journal of Immunology, vol. 152, no. 2, pp. 527-536, 1994.

[39] D. D. Patel, S. F. Wee, L. P. Whichard et al., "Identification and characterization of a 100-kD ligand for CD6 on human thymic epithelial cells," Journal of Experimental Medicine, vol. 181, no. 4, pp. 1563-1568, 1995.

[40] M. A. Bowen, D. D. Patel, X. Li et al., "Cloning, mapping, and characterization of activated leukocyte-cell adhesion molecule (ALCAM), a CD6 ligand," Journal of Experimental Medicine, vol. 181, no. 6, pp. 2213-2220, 1995. 
[41] M. A. Bowen, J. Bajorath, M. D’Egidio et al., "Characterization of mouse ALCAM (CD166): the CD6-binding domain is conserved in different homologs and mediates cross-species binding," European Journal of Immunology, vol. 27, no. 6, pp. 1469-1478, 1997.

[42] J. te Riet, A. W. Zimmerman, A. Cambi et al., "Distinct kinetic and mechanical properties govern ALCAM-mediated interactions as shown by single-molecule force spectroscopy," Journal of Cell Science, vol. 120, no. 22, pp. 3965-3976, 2007.

[43] M. A. Bowen, J. Bajorath, A. W. Siadak et al., "The aminoterminal immunoglobulin-like domain of activated leukocyte cell adhesion molecule binds specifically to the membraneproximal scavenger receptor cysteine-rich domain of CD6 with a 1:1 stoichiometry," Journal of Biological Chemistry, vol. 271, no. 29, pp. 17390-17396, 1996.

[44] M. A. Bowen, A. A. Aruffo, and J. Bajorath, "Cell surface receptors and their ligands: in vitro analysis of CD6-CD166 interactions," Proteins, vol. 40, no. 3, pp. 420-428, 2000.

[45] F. Cortés, F. Deschaseaux, N. Uchida et al., "HCA, an immunoglobulin-like adhesion molecule present on the earliest human hematopoietic precursor cells, is also expressed by stromal cells in blood-forming tissues," Blood, vol. 93, no. 3, pp. 826-837, 1999.

[46] N. J. Hassan, A. N. Barclay, and M. H. Brown, "Frontline: optimal T cell activation requires the engagement of CD6 and CD166," European Journal of Immunology, vol. 34, no. 4, pp. 930-940, 2004.

[47] R. Cayrol, K. Wosik, J. L. Berard et al., "Activated leukocyte cell adhesion molecule promotes leukocyte trafficking into the central nervous system," Nature Immunology, vol. 9, no. 2, pp. 137-145, 2008.

[48] M. C. Levesque, C. S. Heinly, L. P. Whichard, and D. D. Patel, "Cytokine-regulated expression of activated leukocyte cell adhesion molecule (CD166) on monocyte-lineage cells and in rheumatoid arthritis synovium," Arthritis and Rheumatism, vol. 41, no. 12, pp. 2221-2229, 1998.

[49] S. M. A. Abidi, M. K. Saifullah, M. D. Zafiropulos et al., "CD166 expression, characterization, and localization in salivary epithelium: implications for function during sialoadenitis," Journal of Clinical Immunology, vol. 26, no. 1, pp. 12 21, 2006.

[50] S. F. Ofori-Acquah and J. A. King, "Activated leukocyte cell adhesion molecule: a new paradox in cancer," Translational Research, vol. 151, no. 3, pp. 122-128, 2008.

[51] S. F. Wee, W. C. Wang, A. G. Farr et al., "Characterization of a CD6 ligand(s) expressed on human- and murine-derived cell lines and murine lymphoid tissues," Cellular Immunology, vol. 158, no. 2, pp. 353-364, 1994.

[52] Y. S. Joo, N. G. Singer, J. L. Endres et al., "Evidence for the expression of a second CD6 ligand by synovial fibroblasts," Arthritis and Rheumatism, vol. 43, no. 2, pp. 329-335, 2000.

[53] M. K. Saifullah, D. A. Fox, S. Sarkar et al., "Expression and characterization of a novel CD6 ligand in cells derived from joint and epithelial tissues," Journal of Immunology, vol. 173, no. 10, pp. 6125-6133, 2004.

[54] K. T. Stanley, C. VanDort, C. Motyl, J. Endres, and D. A. Fox, "Immunocompetent properties of human osteoblasts: interactions with T lymphocytes," Journal of Bone and Mineral Research, vol. 21, no. 1, pp. 29-36, 2006.

[55] M. R. Sarrias, M. Farnós, R. Mota et al., "CD6 binds to pathogen-associated molecular patterns and protects from LPS-induced septic shock," Proceedings of the National Academy of Sciences of the United States of America, vol. 104, no. 28, pp. 11724-11729, 2007.
[56] J. Vera, R. Fenutría, O. Cañadas et al., "The CD5 ectodomain interacts with conserved fungal cell wall components and protects from zymosan-induced septic shock-like syndrome," Proceedings of the National Academy of Sciences of the United States of America, vol. 106, no. 5, pp. 1506-1511, 2009.

[57] M. Ramos-Casals, J. Font, M. García-Carrasco et al., "High circulating levels of soluble scavenger receptors (sCD5 and sCD6) in patients with primary Sjögren's syndrome," Rheumatology, vol. 40, no. 9, pp. 1056-1059, 2001.

[58] C. Jamin, G. Magadur, A. Lamour et al., "Cell-free CD5 in patients with rheumatic diseases," Immunology Letters, vol. 31, no. 1, pp. 79-83, 1992.

[59] I. Gimferrer, M. Calvo, M. Mittelbrunn et al., "Relevance of CD6-mediated interactions in T cell activation and proliferation," Journal of Immunology, vol. 173, no. 4, pp. 2262-2270, 2004.

[60] A. W. Zimmerman, B. Joosten, R. Torensma, J. R. Parnes, F. N. Van Leeuwen, and C. G. Figdor, "Long-term engagement of CD6 and ALCAM is essential for T-cell proliferation induced by dendritic cells," Blood, vol. 107, no. 8, pp. 3212-3220, 2006.

[61] I. Gimferrer, M. Farnós, M. Calvo et al., "The accessory molecules CD5 and CD6 associate on the membrane of lymphoid T cells," Journal of Biological Chemistry, vol. 278, no. 10, pp. 8564-8571, 2003.

[62] R. Pospisil, G. J. Silverman, G. E. Marti, A. Aruffo, M. A. Bowen, and R. G. Mage, "CD5 is a potential selecting ligand for B-cell surface immunoglobulin: a possible role in maintenance and selective expansion of normal and malignant B cells," Leukemia and Lymphoma, vol. 36, no. 3-4, pp. 353$365,2000$.

[63] S. Garaud, C. Le Dantec, C. Berthou, P. M. Lydyard, P. Youinou, and Y. Renaudineau, "Selection of the alternative exon 1 from the cd5 gene down-regulates membrane level of the protein in B lymphocytes," Journal of Immunology, vol. 181, no. 3, pp. 2010-2018, 2008.

[64] M. A. A. Castro, P. A. Tavares, M. S. Almeida et al., "CD2 physically associates with CD5 in rat T lymphocytes with the involvement of both extracellular and intracellular domains," European Journal of Immunology, vol. 32, no. 5, pp. 1509-1518, 2002.

[65] M. A. A. Castro, R. J. Nunes, M. I. Oliveira et al., "OX52 is the rat homologue of CD6: evidence for an effector function in the regulation of CD5 phosphorylation," Journal of Leukocyte Biology, vol. 73, no. 1, pp. 183-190, 2003.

[66] N. G. Singer, D. A. Fox, T. M. Haqqi et al., "CD6: expression during development, apoptosis and selection of human and mouse thymocytes," International Immunology, vol. 14, no. 6, pp. 585-597, 2002.

[67] H. S. Azzam, A. Grinberg, K. Lui, H. Shen, E. W. Shores, and P. E. Love, "CD5 expression is developmentally regulated by T cell receptor (TCR) signals and TCR avidity," Journal of Experimental Medicine, vol. 188, no. 12, pp. 2301-2311, 1998.

[68] R. Alonso, C. Buors, C. Le Dantec et al., "Aberrant expression of CD6 on B-cell subsets from patients with Sjögren's syndrome," Journal of Autoimmunity, vol. 35, no. 4, pp. 336-341, 2010.

[69] C. M. Bott, J. B. Doshi, C. Morimoto, P. L. Romain, and D. A. Fox, "Activation of human $\mathrm{T}$ cells through CD6: functional effects of a novel anti-CD6 monoclonal antibody and definition of four epitopes of the CD6 glycoprotein," International Immunology, vol. 5, no. 7, pp. 783-792, 1993. 
[70] L. M. Osorio, C. Ordonez, C. A. Garcia, M. Jondal, and S. C. Chow, "Evidence for protein tyrosine kinase involvement in GD6-induced T cell proliferation," Cellular Immunology, vol. 166, no. 1, pp. 44-52, 1995.

[71] L. M. Osorio, M. Rottenberg, M. Jondal, and S. C. Chow, "Simultaneous cross-linking of CD6 and CD28 induces cell proliferation in resting T cells," Immunology, vol. 93, no. 3, pp. 358-365, 1998.

[72] R. L. Kirkman, J. L. Araujo, and G. J. Busch, "Treatment of acute renal allograft rejection with monoclonal anti-T12 antibody," Transplantation, vol. 36, no. 6, pp. 620-626, 1983.

[73] D. C. Roy, R. Tantravahi, C. Murray et al., "Natural history of mixed chimerism after bone marrow transplantation with CD6-depleted allogeneic marrow: a stable equilibrium," Blood, vol. 75, no. 1, pp. 296-304, 1990.

[74] N. C. Patel, J. Chinen, H. M. Rosenblatt et al., "Long-term outcomes of nonconditioned patients with severe combined immunodeficiency transplanted with HLA-identical or haploidentical bone marrow depleted of $\mathrm{T}$ cells with anti-CD6 mAb," Journal of Allergy and Clinical Immunology, vol. 122, no. 6, pp. 1185-1193, 2008.

[75] R. J. Soiffer, D. Fairclough, M. Robertson et al., "CD6-depleted allogeneic bone marrow transplantation for acute leukemia in first complete remission," Blood, vol. 89, no. 8, pp. 3039-3047, 1997. 


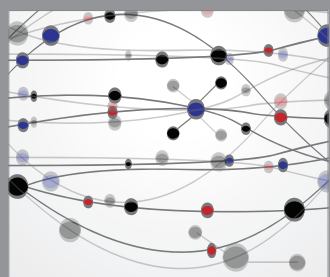

The Scientific World Journal
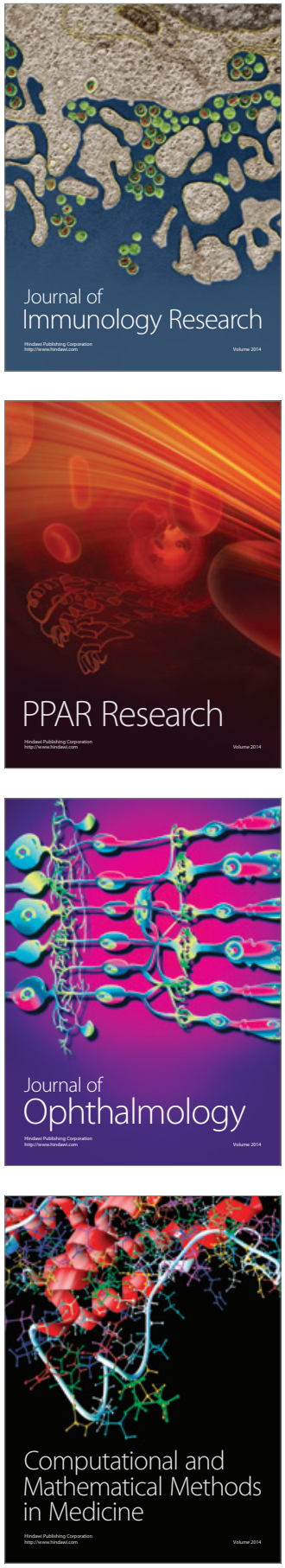

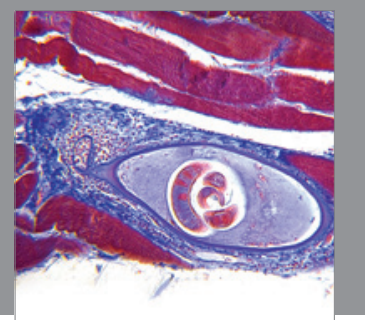

Gastroenterology

Research and Practice
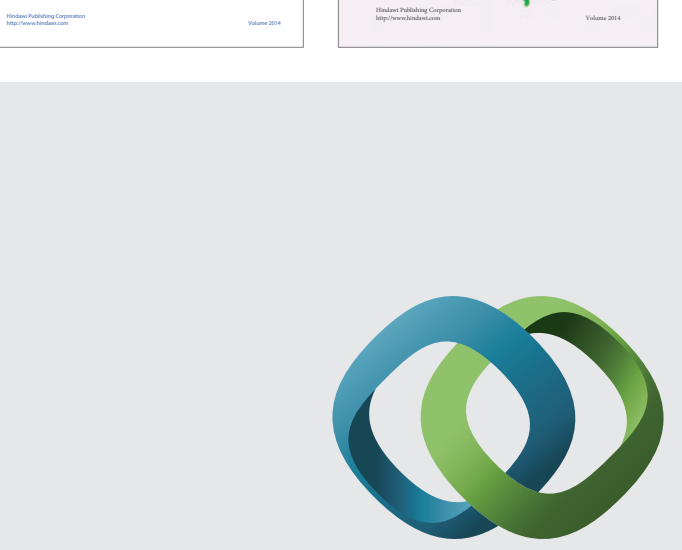

\section{Hindawi}

Submit your manuscripts at

http://www.hindawi.com
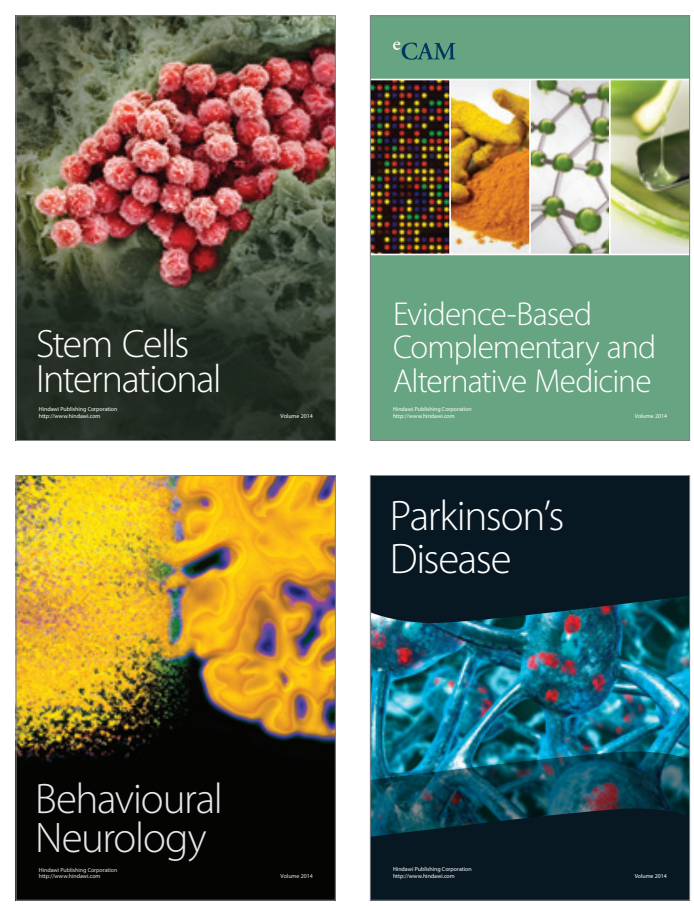

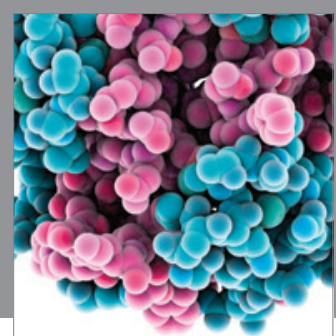

Journal of
Diabetes Research

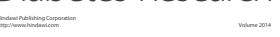

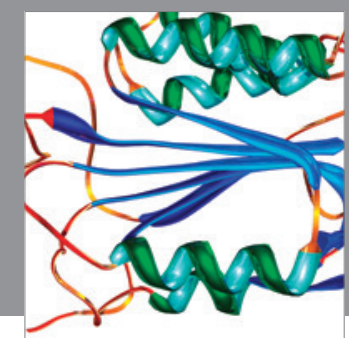

Disease Markers
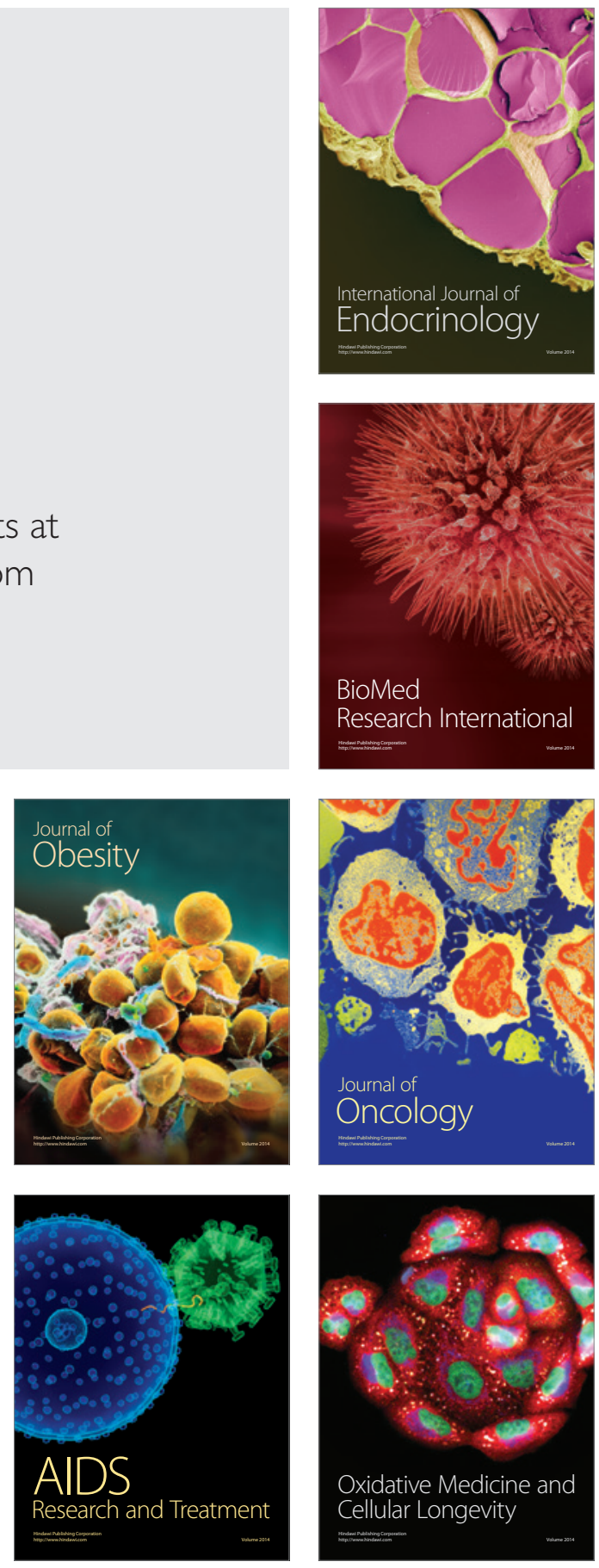